\title{
Normativa de Produção Orgânica no Brasil: a percepção dos agricultores familiares do assentamento da Chapadinha, Sobradinho (DF) ${ }^{1}$
}

\author{
Cindy Marcela Guzmán Muñoz², Miller Germán Solarte Gómez³, \\ João Paulo Guimarães Soares ${ }^{4}$ e Ana Maria Resende Junqueira ${ }^{5}$
}

\begin{abstract}
Resumo: O presente trabalho tem como objetivo determinar o grau de conhecimentos e aderência dos produtores familiares do assentamento rural Chapadinha, em Sobradinho (DF), às normativas de produção orgânica estabelecidas no Brasil. A metodologia de pesquisa utilizada contou com entrevistas abertas que pretenderam avaliar as percepções e conhecimentos dos produtores sobre as normativas mais importantes para a produção orgânica no Brasil: Lei n. 10831/2003; Decreto n. 6323/2007 e a IN n. 46/2011; as normas foram integradas em três unidades de análise: diretrizes dos sistemas e produção, processo de comercialização e mecanismos de controle. O trabalho aponta que a documentação constitui o maior gargalo no processo de certificação de pequenos produtores, pois estes requisitos são complexos, além de que é escassa a capacitação relacionada com o correto entendimento desses documentos. Com relação ao processo de comercialização e os mecanismos de controle identificou-se que os produtores apresentaram um grau de conhecimento incompleto relacionado a alguns dos parâmetros da normativa, prejudicando o tempo para a certificação, sendo necessária maior orientação técnica e acompanhamento.
\end{abstract}

Palavras-chaves: Orgânico; Normativa; Brasil; Produtor familiar; Certificação.

Abstract: This study aims to determine the degree of knowledge and adherence of family farmers of rural settlement Chapadinha, in Sobradinho (DF), to organic production regulations established in Brazil. The research methodology used included open interviews that intended to assess the perceptions and knowledge of the producers on the most important regulations for organic production in Brazil: Law 10831/2003, Decree 6323/2007 and the Normative Instruction 46/2011; these standards had been integrated

1. Data de submissão: 27 de fevereiro de 2015. Data de aceite: 22 de março de 2016.

2. Propaga, Universidade de Brasília. Brasília-DF, Brasil E-mail: cimarguzmu@gmail.com

3. Propaga, Universidade de Brasília. Brasília-DF, Brasil E-mail: ingmi3@hotmail.com

4. Embrapa Cerrados. Planaltina- DF, Brasil. E-mail: jp.soares@embrapa.br

5. Universidade de Brasília. Brasília-DF, Brasil. E-mail: anamaria@unb.br 
into three units of analysis: guidelines of systems and production, marketing processes and control mechanisms. The paper points out that the documentation is the biggest bottleneck in smallholder certification process, as these requirements are complex, and there is less training related to the proper understanding of these documents. In relation to the marketing process and control mechanisms it was identified that the producers have a degree of incomplete knowledge related to some of the rules of the parameters related to these aspects, damaging time for certification, requiring greater technical guidance and monitoring.

Key-words: Organic; Normative; Brazil; Family producer; Certification.

Classificação JEL: Q16.

\section{Introdução}

A agricultura tem evoluído por meio do desenvolvimento de novas tecnologias, maquinários agrícolas e da indústria química que, tendo estimulado a produção de alimentos, também resultou em consequências visíveis sobre o meio ambiente e os ecossistemas. Em função das consequências, foi-se gerando uma pressão da sociedade pelo consumo de produtos obtidos em sistemas produtivos que não geraram impactos sobre o meio ambiente e a saúde humana. A agricultura orgânica é um sistema de produção alternativo seguro e sustentável, baseado na interação dinâmica entre o solo, as plantas, os animais, as pessoas, o ecossistema e o meio ambiente (IFOAM, 1998).

Essa pressão gerada pela sociedade representa a necessidade de mecanismos reguladores da qualidade dos produtos orgânicos, que envolverem o desempenho ambiental do processo de produção; mecanismos exibidos hoje nas normativas orgânicas e ambientais, que devem ser cumpridos para que os produtores obtenham a certificação (PESSOA, 2002). No Brasil, podem-se distinguir três sistemas certificação orgânica, a Organização de Controle Social(OCS), os Sistemas Participativos de Avaliação da Conformidade Orgânica e a Certificação por Auditoria, que tem como objetivo comum classificar e padronizar as atividades agrícolas utilizadas na produção orgânica, baseando-se na normativa e regulamentos nacionais buscando garantir a qualidade dos sistemas de produção (PINHEIRO, 2012).

Buscar adequar-se às normativas e regulamentos legais seguidos pelas certificadoras pode ser considerado pelos pequenos produtores familiares como uma barreira no caminho para a certificação, barreira gerada principalmente pela falta de informação e o desconhecimento referente à legislação, uma vez que, além disso, existe no meio cientifico uma confusão entre Agroecologia e sistemas orgânicos de produção e aqueles produtos gerados de forma alternativa (FIGUEIREDO e SOARES, 2012).

O sistema orgânico se enquadra no contexto da agroecologia, sendo definido como um sistema de produção que não permite o uso de "agrotóxicos", medicamentos químicos, hormônios sintéticos e de produtos transgênicos, restringe a utilização de adubos químicos, inclui ações de conservação dos recursos naturais e considera aspectos éticos nas relações sociais internas da propriedade e no trato com os animais (KHATOUNIAN, 2001). Portanto, pela legislação brasileira, todas as terminologias doravante utilizadas serão consideradas para produtos de origem vegetal e animal no Brasil como orgânicos; contudo, nos sistemas orgânicos, todas as práticas e processos previstos pela ciência agroecologia 
podem e devem ser aplicados (FIGUEIREDO e SOARES, 2012), desde que em conformidade com a legislação produção orgânica (BRASIL, 2011a).

O assentamento Chapadinha é o primeiro assentamento da reforma agrária agroecológica no Distrito Federal, segundo a Federação de Agricultores e Agricultoras da Agricultura Familiar (Fetraf). Por meio do programa de Produção Agroecológica Integrada Sustentável (Pais), que em 2008 possuía 82 unidades acompanhadas, apoiadas pela Fundação Banco do Brasil, em parceria com do Serviço de Apoio às Pequenas e Médias Empresas do Distrito Federal (DF), a Empresa de Assistência Técnica e Extensão Rural do Distrito Federal (Emater-DF) e a Associação dos Trabalhadores Rurais da Agricultura Familiar do Assentamento Chapadinha (Astraf-DF), do total das unidades de produção naquele período, apenas 11 eram certificadas para a produção orgânica.

Ainda que a produção orgânica apresente uma tendência crescente, é escassa a produção científica que faça uma caracterização dos produtores que acolheram aquele sistema produtivo. Tem-se que estes produtores são enquadrados num grupo homogêneo, assumindo que, pelo fato deles conduzirem sistemas produtivos sob práticas tradicionais, estão cumprindo com a normativa orgânica de produção. Nesse contexto, o presente trabalho se justifica pela necessidade de trazer um pouco mais de detalhes a respeito deste grupo de produtores e de determinar o grau de conhecimento dos produtores do assentamento Chapadinha, localizado no Lago Oeste, Sobradinho (DF), das normas de produção orgânica no Brasil e seu nível de aderência em relação às práticas regulamentadas pela norma.

\section{Fundamentação teórica}

\subsection{Produção orgânica}

No início dos anos 1920, foi gestado um conjunto de movimentos que visou o desenvolvimento de um tipo de agricultura alternativa à convencional, tendo como uns dos princípios a conservação e proteção do meio ambiente e o reaproveitamento de recursos internos da propriedade (DE AQUINO e DE ASSIS, 2005). A agricultura orgânica é consequência de um desses movimentos, tendo crescido de importância ao longo do tempo (DE AQUINO e DE ASSIS, 2005).

De Jesus (2005) relata que uma das primeiras abordagens da agricultura orgânica foi proposta por Sir Albert Howard, conhecido como o pai moderno da agricultura orgânica e quem ressaltou que "a saúde do solo, planta, animal e o homem é uma e indivisível". De Jesus (2005) salienta a crítica de Howard na obra "An agricultural testament" (HOWARD, 1943) em relação aos métodos de produção convencional, trabalho que teve repercussões em diversos países, como a Inglaterra, onde foi fundada a Soil Association, uma das primeiras instituições a apoiar a produção agrícola orgânica e que é atualmente a mais importante entidade inglesa no que tange à difusão, organização, padronização, certificação e apoio à agricultura orgânica (DE JESUS, E. L, 2005).

O trabalho de Howart também teve repercussões nos Estados Unidos, onde nos anos 1940 Jerome Irving Rodale fundou uma editora que publicava várias revistas e muitos livros, sobre a saúde e o bem-estar gerados a partir do consumo de alimentos orgânicos. Além de difundir o termo "orgânico" para significar os produtos agrícolas cultivados sem pesticidas; Rodale também fundou o Rodale Instititute, que até hoje desenvolve pesquisa, extensão e formação em agricultura orgânica (IFOAM, 2014a).

Devido ao crescimento da produção e popularidade dos alimentos orgânicos, foi criada em 1972 a Federação Internacional dos movimentos de agricultura orgânica, ou "International Federation of Organic Agriculture Movements" (IFOAM), entidade encarregada de adotar um posicionamento oficial sobre a produção orgânica a nível internacional (IFOAM, 2014).

Desde setembro de 2005, durante a Assembleia Geral da IFOAM na Austrália, foi aprovada a moção que estabeleceu uma definição concreta e 
364 - Normativa de Produção Orgânica no Brasil: a percepção dos agricultores familiares do assentamento da Chapadinha, Sobradinho (DF)

clara do que é a agricultura orgânica e que descreve sua verdadeira essência (IFOAM, 2013).

\subsection{O que é a produção orgânica?}

Durante as sessões que foram feitas em Vingola, Italia pela IFOAM em 2008, a definição de produção orgânica foi proposta para sua ratificação (IFOAM, 2013):

[...] a agricultura orgânica é um sistema de produção que mantém a saúde dos solos, dos ecossistemas e as pessoas. Baseia-se nos processos ecológicos, na biodiversidade e nos ciclos adaptados às condições locais, substituindo a utilização de insumos com efeitos adversos. A agricultura orgânica combina a tradição, a inovação e a ciência para o benefício do meio ambiente compartilhado e promover relações justas e uma boa qualidade de vida para todos os envolvidos.

\subsection{A produção orgânica no mundo e no Brasil}

Nos últimos anos, o crescimento da produção orgânica no mundo tem sido dinâmico e constante (GALINDO, 2007). O incremento das áreas dedicadas à agricultura orgânica no mundo entre 1999 e 2012 representou um aumento de mais de $240 \%$ na extensão de produção orgânica em milhões de hectares, passando de 11 milhões de hectares a 37,5 (IFOAM e FIBL, 2014).

Dentre as regiões com maior área agrícola orgânica no mundo, segundo a IFOAM (2014) para 2012, encontram-se a Oceania, com 12,2 milhões de hectares, seguida por Europa, com 11,2 milhões de hectares; já, Ásia, América do Norte e África possuem 6,8 milhões de hectares: 3,2 milhões, 3 milhões e 1,1 milhão de hectares, respectivamente.

Referindo-se à quantidade de área agrícola orgânica por país segundo registros do estudo The World of Organic Agriculture realizado em 2010 pelo Research Institute of Organic Agriculture (FIBL) e pelo IFOAM, encontra-se em primeiro lugar a Austrália, com 12 milhões de hectares, seguido de Argentina, com 4,4 milhões de hectares e, em um terceiro lugar, China, com 1,9 milhões de hectares. Considerando o referido estudo, o Brasil, com 1,8 milhões de hectares, posiciona-se como a quarta maior área orgânica do mundo (IFOAM e FIBL, 2014).

De acordo com o Ministério da Agricultura, Pecuária e Abastecimento (Mapa) (2014), a área total do País com produção orgânica certificada em 2013 representou 1,8 milhão de hectares aproximadamente, manejados por 6.719 produtores em mais de 10.000 unidades produtivas. A agricultura orgânica é encontrada em todos os estados brasileiros, mas em termos de produção orgânica por área tem-se que Mato Grosso e Pará são os estados com maior quantidade de terras dedicado a este tipo de agricultura com mais de 622.000 e 602.000 hectares, respectivamente, seguidos por Amapá, com 132.000 ha, Rondônia, com 36.000 ha e Bahia, com 25.000 ha (MAPA, 2012; RABELLO, 2012).

\subsection{Normativa orgânica no Brasil}

Na década de 1970, a agricultura moderna, caracterizada pelo uso intensivo de insumos sintéticos e agroquímicos e pelo excessivo revolvimento do solo, fez com que a grande vertente ecológica que se gestava no Brasil se unisse ao movimento orgânico, que na época estava mais relacionado com filosofias que buscavam o retorno do contato do homem com a terra como uma alternativa de vida (ORMOND et al., 2002).

Nessa mesma época, foi criada a Federação Internacional do Movimento da Agricultura Orgânica (International Federation of the Organic Agriculture Movement, IFOAM), organização que desde 1972 é a encarregada de harmonizar os conceitos e estabelecer padrões básicos da agricultura orgânica; padrões que são aceitos em todo o mudo servindo como base para a regulamentação e o trabalho de certificação de numerosas entidades certificadoras a nível mundial, segundo a IFOAM (2014).

No Brasil, o Ministério de Agricultura, considerando a crescente demanda por produtos 
orgânicos, sistemas ecológicos, biológicos, biodinâmicos e agroecológicos, além da exigência dos mercados por produtos naturais, resolveu estabelecer normativas de produção, tipificação, processamento, embalagem, distribuição, identificação e de certificação para os produtos orgânicos de origem vegetal e animal, por meio da instrução normativa 007 de 1999 (SILVA, 2003).

Como exposto no Quadro 1 que representa um resumo da normativa orgânica no Brasil, em ordem cronológica, a legislação orgânica define as práticas empregadas na produção de alimentos tendo em conta normas orgânicas, que por sua vez são constituídas de um conjunto de requisitos que devem ser aplicáveis pelos agricultores, processadores e os comerciantes; assim, qualquer produtor ou operador que pretenda comercializar seus produtos como orgânicos deve, na maioria das vezes, cumprir com pelo menos uma norma de caráter orgânico e tem que ser certificado com esta norma (IFOAM, 2013). De forma similar, se faz evidente que no mundo não existe uma normativa comum ou geral que possa ser aplicada às produções que se regem sob práticas agrícolas orgânicas, pois cada país regula de forma independente o mercado dos produtos orgânicos, e a maioria dos países dispõe de legislações básicas.

De acordo com a IFOAM (2013), existe um grande número de normas orgânicas no mundo, algumas das quais são governamentais, outras são normativas de caráter privado, algumas são muito especificas para cada região. No comércio feito entre sistemas baseados em normas distintas requer-se que estes sistemas tenham um reconhecimento e aceitação entre si. A IFOAM tem desenvolvido um conjunto de normas aprovadas oficialmente como orgânicas pelo movimento orgânico internacional, e que de alguma forma traçam um critério para distinguir entre orgânico e não orgânico. A aprovação de cada norma é baseada numa avaliação técnica detalhada destas, seguindo um procedimento determinado pelo sistema de garantia orgânica da IFOAM (2013).

Quadro 1. Principal Normativa orgânica no Brasil

\begin{tabular}{|l|l|}
\hline \multicolumn{1}{|c|}{ Normativa } & \multicolumn{1}{c|}{ Definição } \\
\hline $\begin{array}{l}\text { Foro Global de Organizações Não } \\
\text { Governamentais e Movimentos } \\
\text { Sociais - ECO 92 }\end{array}$ & $\begin{array}{l}\text { Foram tratados temas relacionados com a agricultura sustentável, segurança alimentar, } \\
\text { água potável e recursos pesqueiros de forma a assegurar qualidade ambiental e alimentar, } \\
\text { resultando na construção de estratégias de desenvolvimento sustentável denominada a } \\
\text { Agenda 21 (CAMARG, 2002). }\end{array}$ \\
\hline $\begin{array}{l}\text { Portaria MA n. } 178 \text { de agosto de } \\
1994\end{array}$ & $\begin{array}{l}\text { Criação da comissão especial para propor normas de certificação de produtos orgânicos } \\
\text { (CAMARGO, 2002). }\end{array}$ \\
\hline $\begin{array}{l}\text { Instrução Normativa (IN) n. 007 de } \\
1999\end{array}$ & $\begin{array}{l}\text { Dispõe sobre normas para a tipificação, processamento, envase, distribuição, identificação } \\
\text { e certificação da qualidade de produtos orgânicos, foram de origem animal ou vegetal } \\
\text { (BRASIL, 1999). }\end{array}$ \\
\hline Lei n. 10.831 de 2003 & $\begin{array}{l}\text { Conceitos a respeito da produção orgânica, a finalidade de um sistema de produção } \\
\text { orgânico, e estabelece alguns parâmetros em relação à certificação, inspeção e fiscalização } \\
\text { da produção (BRASIL, 2003). }\end{array}$ \\
\hline Decreto n. 6.323 de 2007 & $\begin{array}{l}\text { Regulamenta a Lei n. 10.831 de 2003, sem prejuízo do cumprimento das demais normas que } \\
\text { estabeleçam outras medidas relativas à qualidade dos produtos e processos (BRASIL, 2008). }\end{array}$ \\
\hline $\begin{array}{l}\text { Instrução Normativa (IN) n. 46 de } \text { de } \\
2011\end{array}$ & $\begin{array}{l}\text { Desde 1o. de janeiro de 2011 passa a ser fiscalizada pela legislação brasileira (Lei n. 10.831), } \\
\text { todos os sistemas de produção que não são convencionais a se autointitularem "orgânicos" e } \\
\text { usarem o novo selo do Sistema Brasileiro de Avaliação da Conformidade Orgânica somente } \\
\text { após passarem pelo crivo das instituiçóes certificadoras autorizadas. A IN 64/2008 foi } \\
\text { revogada e entrou em vigor a IN 46/2011, que incluiu algumas modificações (BRASIL, 2011). }\end{array}$ \\
\hline
\end{tabular}

Fonte: Adaptado de Brasil (1999, 2003, 2008, 2011); Camargo (2002). 
366 - Normativa de Produção Orgânica no Brasil: a percepção dos agricultores familiares do assentamento da Chapadinha, Sobradinho (DF)

\subsection{Processo de certificação orgânica no Brasil}

De acordo com o Mapa (2009), existem três mecanismos de certificação implementados no Brasil para que os produtores possam ser reconhecidos como produtores orgânicos:

\subsubsection{Organização de controle social}

Mecanismo disposto para os pequenos produtores, que pode aplicar-se partindo de fiscalizações entre os mesmos produtores de uma região iniciando com criação da Organização de Controle Social (OCS). Esta organização pode ser conformada por um grupo, associação, cooperativa ou consórcio, com ou 'sem personalidade jurídica, de agricultores familiares. Quando necessário, deve-se consultar sobre decisões técnicas a Comissão de Produção Orgânica (CPOrg) da unidade onde estiver alocado. No momento em que um produtor este vinculado a uma OCS e cumpra com os requisitos propostos, obtém a declaração de registro que garante ao consumidor um produto orgânico. Dessa forma, o produtor pode vender de forma direta ao consumidor nas feiras de produtos orgânicos (MAPA, 2009).

\subsubsection{Sistemas participativos de avaliação da conformidade orgânica}

São redes socioparticipativas em que a certificação dos produtores é baseada na ativa participação dos atores envolvidos, e os sistemas são construídos fundamentando-se na confiança, em redes sociais e na troca de conhecimento. Ao debater, trocar experiências e fazer sugestões a seus pares, os agricultores asseguram sua participação e inclusão no processo (MAPA, 2009). A discussão aberta em relação às normas e procedimentos da rede garante a transparência da certificação participativa; da mesma forma, gerenciando a discussão sem atores externos para sua regulação, os produtores ganham cada vez mais autonomia. Estas redes conformam núcleos regionais para facilitar o processo de certificação (ANGEOLETTO et al., 2012).

\subsubsection{Certificação por auditoria}

Desenvolve-se a partir das leis nacionais, mas implica custo elevado que vai depender de vários fatores como a taxa de inscrição, o tamanho da área que vai ser certificada, a elaboração de relatórios, a análise de laboratório de solo e a água, visitas de inspeção e o acompanhamento e emissão do certificado (OLIVEIRA, 2011). A certificação por auditoria pode ser feita por agências locais, internacionais ou por associações entre agências; encontrando-se diversidade de certificadoras atuantes no Brasil, de origem nacional, como a Associação de Agricultura Orgânica de São Paulo (AAO), a Associação de Agricultura Orgânica (AAOCERT); entre as certificadoras internacionais destacam-se a norte-americana Farmers Verified Organic (FVO), a francesa Ecocert Brasil, a alemã BCS Öko-Garantie $\mathrm{GmbH}$, a holandesa associação Skal Brasil Certificadora (SKAL), e a suíça IMO Control do Brasil Ltda. (ANGEOLETTO et al., 2012).

\subsection{O selo obtido}

Uma vez credenciada e acreditada, a propriedade pode gerar diversos produtos certificados que recebem o selo de qualidade, desde que se observem os requisitos de qualidade, rastreabilidade, sustentabilidade e padrão de vida dos produtores (MAPA, 2014). É de importância ter em conta que o selo obtido pelos mecanismos de certificação, tanto participativos de avaliação de conformidade orgânica quanto de certificação por auditoria, são diferentes (Figura 1).

Figura 1. Selos dos produtos orgânicos no Brasil
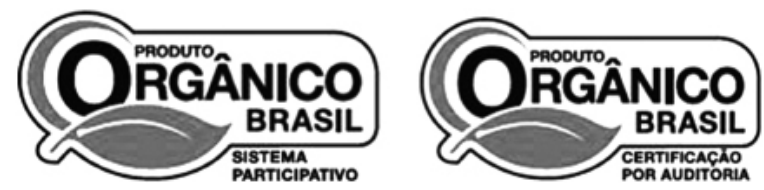

Fonte: Mapa (2014).

De acordo com as normas e os regulamentos que foram descritos, além dos outros que 
fazem parte da legislação orgânica brasileira, os produtos orgânicos certificados devem adotar o selo, exceto no caso dos produtores que fazem a venda direta aos consumidores, caso da OCS (ALVES et al., 2012).

\section{Metodologia}

Para atender os objetivos propostos, o estudo foi desenvolvido sob uma abordagem qualitativa com um desenho de pesquisa baseado em estudo de caso, pois a pesquisa foi desenvolvida com um grupo específico de produtores com características particulares no assentamento de Chapadinha, localizado no Lago Oeste, em Sobradinho, Distrito Federal, onde atualmente moram 42 produtores, dos quais 23 são vinculados a uma Organização de Controle Social (OCS). Cada produtor recebeu 10 hectares para trabalhar a terra; cujo termo de posse ocorreu no período 2006-2010. Desde então, tem sido estimulada a adoção da produção orgânica. A escolha deste assentamento justificou-se pelo fato de a Chapadinha ter sido o primeiro assentamento da Reforma Agrária Agroecológica no Distrito Federal (FETRAF-BRASIL, 2012), em que os produtores deveriam conhecer e aplicar a normativa para produção orgânica e iniciar um processo de certificação.

\subsection{Coleta de dados}

A coleta de dados foi realizada no período de março a maio de 2014, com o acompanhamento do serviço de extensão da Sebrae, mediante o desenvolvimento de visitas in loco nas unidades produtivas. A técnica para a coleta de dados foi baseada em entrevistas estruturadas, aplicadas a oito produtores orgânicos, as quais incluíam uma ampla gama de informações sobre normativa e certificação orgânica, com o objetivo de avaliar o grau de conhecimento dos produtores nessa temática.

No Quadro 2 são apresentados os aspectos avaliados junto aos produtores rurais a partir da criação de um modelo no qual foram resumidas as principais características das normativas mais

Quadro 2. Aspectos objetos do estudo e avaliação junto aos produtores do Assentamento Chapadinha, Lago Oeste (DF), com base na da legislação e certificação orgânica brasileira

\begin{tabular}{|c|c|c|c|}
\hline Unidade de Análise & Pontos Criticos & Indicadores & Critérios de Avaliação \\
\hline \multirow[t]{3}{*}{$\begin{array}{l}\text { 1. Diretrizes dos } \\
\text { sistemas e produção }\end{array}$} & a) Rastreabilidade & Evidências físicas de registro & $\begin{array}{l}\text { O produtor tem documentação das ativida- } \\
\text { des que desenvolve? }\end{array}$ \\
\hline & b) Processo de conversão & Período de conversão & $\begin{array}{l}\text { Qual é o tempo de transição agroecológica da } \\
\text { propriedade? Tem algum registro que demos- } \\
\text { tre isso? }\end{array}$ \\
\hline & c) Plano de manejo & $\begin{array}{l}\text { Histórico da utilização da área; manu- } \\
\text { tenção ou aumento da biodiversidade; } \\
\text { manejo dos resíduos; conservação do } \\
\text { solo e da água; manejo produção ani- } \\
\text { mal e vegetal; procedimentos para pós- } \\
\text {-produção. }\end{array}$ & $\begin{array}{l}\text { O produtor tem registos do plano de manejo } \\
\text { orgânico de sua propriedade? } \\
\text { Conhece os requerimentos para produzir de } \\
\text { forma orgânica? }\end{array}$ \\
\hline \multirow[t]{2}{*}{$\begin{array}{l}\text { 2. Processo de } \\
\text { comercialização }\end{array}$} & $\begin{array}{l}\text { a) Isolamento produtos orgânicos } \\
\text { dos convencionais. }\end{array}$ & $\begin{array}{l}\text { Diferenciação de produtos convencio- } \\
\text { nais; proteção contra sustâncias não } \\
\text { autorizadas. }\end{array}$ & $\begin{array}{l}\text { O produtor separa os produtos orgânicos dos } \\
\text { convencionais? }\end{array}$ \\
\hline & b) Identificação do fornecedor & Certificação como produtor orgânico & $\begin{array}{l}\text { O produtor tem declaração de cadastro como } \\
\text { orgânico ou selo? }\end{array}$ \\
\hline $\begin{array}{l}\text { 3. Mecanismos de } \\
\text { controle }\end{array}$ & $\begin{array}{l}\text { Ações de fiscalização da produção } \\
\text { e comercialização. }\end{array}$ & $\begin{array}{l}\text { Medidas de fiscalização; penalidades } \\
\text { administrativas. }\end{array}$ & $\begin{array}{l}\text { O produtor conhece as medidas de fiscaliza- } \\
\text { ção e as penalidades? } \\
\text { Tem sido aplicada alguma destas modalida- } \\
\text { des de fiscalização a seus produtos? }\end{array}$ \\
\hline \multirow[t]{2}{*}{ 4. Certificação } & $\begin{array}{l}\text { a) Cumprimento dos requisitos } \\
\text { para a certificação. }\end{array}$ & $\begin{array}{l}\text { Conhecimento e aderência do produtor } \\
\text { às normas. }\end{array}$ & $\begin{array}{l}\text { O produtor cumpre com os mínimos requisi- } \\
\text { tos exigidos pelos mecanismos de certificação? }\end{array}$ \\
\hline & $\begin{array}{l}\text { b) Mecanismo de certificação or- } \\
\text { gânica. }\end{array}$ & Custos de certificação. & $\begin{array}{l}\text { Qual mecanismo de certificação orgânica é o } \\
\text { mais exequível para o produtor? }\end{array}$ \\
\hline
\end{tabular}

Fonte: Adaptado do caderno do Plano de Manejo orgânico (BRASIL, 2011b). 
368 - Normativa de Produção Orgânica no Brasil: a percepção dos agricultores familiares do assentamento da Chapadinha, Sobradinho (DF)

importantes para a produção orgânica no Brasil quais sejam, a Lei n. 10831 de 2003, Decreto n. 6323 de 2007 e a Instrução Normativa 46 de 2011, assim como os principais pontos críticos da certificação orgânica. Para maior inclusão, essas normas foram integradas em quatro unidades de análise, estabelecendo os pontos críticos para cada uma delas, construindo indicadores e estabelecendo o critério de avaliação que, em forma de questões abertas, foram incluídas no desenvolvimento das entrevistas aplicadas aos produtores, com base no caderno do Plano de Manejo Orgânico (BRASIL, 2011b).

\subsection{Procedimento de análise}

Os dados foram analisados mediante a ferramenta análise de conteúdo, aplicando as três fases propostas por Mozzato e Grzybovski (2011) para seu desenvolvimento: (a) Pré-Análise, na qual é organizado o material a ser analisado tendo em conta três etapas: estabelecimento de contato com os documentos da coleta de dados, escolha dos documentos que serão analisados e determinação de indicadores; (b) Exploração do Material, a partir da definição de categorias (codificação), identificação das unidades de registro e identificação das unidades de contexto nos documentos; e (c) o tratamento dos resultados, inferência e interpretação mediante a condensação e o destaque das informações para análise, culminando nas interpretações.

\section{Resultados e discussão}

\subsection{Principais características das unidades analisadas}

Como foi apresentado na parte metodológica, a pesquisa foi desenvolvida com oito produtores do assentamento de Chapadinha, região do Lago Oeste, Sobradinho, Distrito Federal, onde cada produtor constitui-se em uma unidade de análise. No Quadro 3 são apresentadas as principais características dos produtores para depois aprofundar nas características comuns e particularidades de cada um deles.

Inicialmente, é importante reconhecer que, antes de produzir de forma orgânica, as principais culturas cultivadas por todos os produtores entrevistados foram milho e mandioca, mas em uma pequena escala e usando baixas quantidades de adubos químicos, os quais geralmente foram doados pelo governo. Já uma vez iniciada a produção orgânica, as unidades apresentaram características comuns em relação a aspectos como: a área total de todas as propriedades é dez hectares, das quais os produtores concentram sua produção orgânica em aproximadamente um hectare, e o restante é usado para reflorestamento ou manutenção de animais como porcos, gado e galinhas, tentando manter as práticas orgânicas em toda sua propriedade.

O tempo de produção orgânica tem variação entre dois e quatro anos. Os produtos obtidos nas

Quadro 3. Características dos produtores avaliados

\begin{tabular}{|c|c|c|c|}
\hline Produtor & Tempo de produção orgânica & Tipo de certificação & Tempo de certificação \\
\hline 1 & 4 & OCS & 2 \\
\hline 2 & 3 & OCS & 1 \\
\hline 3 & 4 & OCS & 2 \\
\hline 4 & 2 & OCS & 1 \\
\hline 5 & 2 & OCS & 1 \\
\hline 6 & 3 & OCS & 2 \\
\hline 7 & 2 & OCS & 1 \\
\hline 8 & 2 & OCS & 1 \\
\hline
\end{tabular}

Fonte: Elaboração própria. 
unidades são principalmente hortaliças, frutíferos, mandioca, milho, galinhas e ovos. Quanto ao processo de certificação desenvolvido pelos produtores familiares de Chapadinha, constituiu-se como caraterística comum a Organização de Controle Social de certificação (OCS). Isso, segundo os produtores entrevistados, teve sua justificativa pelo trabalho associativo que tem sido desenvolvido desde as iniciativas de produção orgânica, que permitiu um processo de certificação mais participativo e de aprendizagem mútua, além de não representar custos no seu desenvolvimento. De acordo com a produtora 3, o desenvolvimento da OCS tem sido muito importante no momento de fazer a comercialização do produto, pois embora não tenham selo orgânico, podem fazer venda direta de seus produtos, sendo estes valorados e pagos como orgânicos nas feiras livres e no canal institucional.

O tempo de certificação varia entre um e dois anos, sendo necessário um processo de aprendizagem que, segundo o produtor 6 , tem sido rigoroso, pois além de produzir de uma forma diferente, os produtores têm tido que assimilar diversas informações das normativas que devem ser cumpridas, as quais, segundo o produtor, caracterizam-se por apresentar burocracia e complicações para os pequenos produtores, exigindo registros minuciosos para o caso de uma produção familiar. A produtora 2 também afirmou que há falta de informação sobre a exigência de tais requisitos e de adequação dessas tecnologias para o gerenciamento da produção orgânica, pois as capacitações são quase sempre dirigidas aos labores de produção e comercialização, e as questões normativas têm sido pouco aprofundadas. Além disso, desde o final de 2013, os produtores encontram-se numa fase preparatória para desenvolver a certificação realizada através de um Organismo Participativo de Avaliação da Conformidade (Opac) - Cerrado, credenciado pelo Ministério da Agricultura, Pecuária e Abastecimento (Mapa), a qual é baseada na relação de confiança e participação dos envolvidos no sistema (produtores, consumidores, técnicos, entre outros) para que haja a garantia da qualidade do produto orgânico
(BRASIL, 2009). Com esta certificação, os produtores da Chapadinha avaliados poderão obter o selo de produção orgânica, mas as exigências quanto ao conhecimento e aplicação da normativa serão cada vez maiores, assim como seu compromisso pela produção de alimentos saudáveis.

Nesse contexto, perto do início de um processo de certificação mais avançado, no próximo item serão apresentadas as principais percepções dos produtores avaliados na Chapadinha sobre a legislação orgânica no Brasil.

\subsection{A normativa percebida pelos agricultores}

A agricultura orgânica surge como alternativa para os produtores familiares aos problemas decorrentes da produção convencional como a inadequação econômica, social e ambiental. Embora este sistema de produção seja de fácil implantação na pequena propriedade, além da sua similaridade com os conhecimentos tradicionais dos produtores, ao enfrentar a realidade destas pessoas salienta-se que as legislações brasileiras foram uma barreira para o crescimento destas unidades neste mercado (PINHEIRO, 2012). $\mathrm{Na}$ continuação serão apresentados os principais pontos críticos que os produtores avaliados na Chapadinha devem enfrentar ao se adequar à normativa orgânica.

\subsection{Diretrizes dos sistemas de produção}

Para efeitos da pesquisa foram levados em conta três diretrizes referentes aos sistemas de produção orgânica de acordo com a normativa:

\subsubsection{Rastreabilidade}

De acordo com a IN 46 no Art. 7o do capítulo II que trata da documentação e do registro, a unidade de produção orgânica tem a obrigação de possuir registros dos procedimentos de todas as operações envolvidas na obtenção dos produtos orgânicos e sua manutenção por um período mínimo de 5 (cinco) anos (BRASIL, 2011). A finalidade da rastreabilidade é controlar um lote de 
produção, desde a colheita até o transporte, ou até uma operação imersa na cadeia de produção em que o produto sofre algum processo ou tratamento (MOE, 1998).

De acordo com os dados obtidos, a totalidade dos produtores avaliados concorda que este tópico (rastreabilidade) foi nomeado em algumas ocasiões dentro das capacitações que eles têm por parte dos órgãos governamentais que os assistem em questões de produção, mas nenhum dos produtores possuem os registros; eles afirmaram ter registros em cadernos ou livretas, assim como algumas das faturas de insumos, mas em nenhum momento foram apresentados. Neste sentido, Pinheiro (2012), que realizou um estudo visando identificar as dificuldades em relação aos aspectos ambientais e legais para a obtenção da certificação orgânica de modo auditada numa associação agrícola de base familiar denominada APEP, no município de Palmeira, encontrou que todas as unidades orgânicas pesquisadas desconheciam a necessidade da rastreabilidade. De acordo com a mesma autora, os requisitos dispostos nas leis referentes a este tópico são complexos, aumentando o desconhecimento da normativa por esses produtores, além de salientar a escassa capacitação com relação à elaboração desses documentos. Os produtores avaliados na Chapadinha poderiam cumprir com este item tão importante na legislação, pois possuem capacitação suficiente a respeito da normativa orgânica.

\subsubsection{Processo de conversão}

O processo de conversão encontra-se imerso na seção II que trata da duração do período de Conversão, do capítulo IV da IN 46, que estabelece que o período de conversão será variável de acordo com o tipo de exploração e a utilização anterior da unidade de produção, considerando a situação ecológica e social atual, com duração mínima de 12 (doze) meses de manejo orgânico na produção vegetal de culturas anuais, para que a produção do ciclo subsequente seja considerada como orgânica (BRASIL, 2011). Nesta questão, de acordo com as respostas dadas pelos produtores, todos eles cumpriram com os doze (12) meses de conversão exigidos pela normativa. O produtor três (3) expressou que cada um dos produtores que tem interesse em ingressar à associação de produtores da Chapadinha e obter a certificação pela OCS deve cumprir com este período de desintoxicação do solo; desta forma, os produtores já tinham passado pelo período de conversão exigido pela normativa.

Neste mesmo sentido, a IN 46 estabelece que a decisão da data a ser considerada como ponto de partida do período de conversão terá como base as informações levantadas nas inspeções ou visitas de controle interno que deverão verificar a compatibilidade da situação encontrada com os regulamentos técnicos, por meio de elementos comprobatórios, tais como declarações de órgãos oficiais relacionados às atividades agropecuárias, declarações de órgãos ambientais oficiais, entre outros (BRASIL, 2011). Assim, encontrou-se que nenhum dos produtores conta com os elementos comprobatórios que acreditem o cumprimento desta atividade. Os mesmos não estão cumprindo com mais um requisito legal, embora tenham todo o conhecimento teórico e prático do significado de período de conversão.

Da mesma forma, Pinheiro (2012) encontrou que a média do período de conversão dos produtores da APEP foi de aproximadamente cinco (5) anos, cumprindo com as exigências legais, mas desconheciam a necessidade de um documento declarado por terceiros que comprovasse que a unidade passara por esse período de conversão. Demostra-se, então, que a falta de conhecimento da normativa orgânica faz com que os produtores avaliados na chapadinha estejam infringindo algumas das exigências legais; exigências relevantes quando se trata da qualidade de um produto orgânico.

\subsubsection{Plano de manejo}

O plano de manejo da produção orgânica é um documento que visa descrever um histórico das atividades técnicas implementadas na obtenção dos produtos orgânicos, verificando que cada 
uma das atividades está em conformidade com a normativa orgânica brasileira (BRASIL, 2011). Na IN 46, o capítulo III do seu Título I, requisitos gerais dos sistemas orgânicos de produção, estabelece a obrigatoriedade da disposição do Plano de Manejo orgânico atualizado por parte de todas as unidades de produção orgânica, assim como para o período de conversão que, de acordo à normativa, deverá ser elaborado de forma específica, contemplando os regulamentos técnicos e todos os aspectos relevantes do processo de produção.

O Plano de Manejo Orgânico deverá contemplar quesitos como o histórico de utilização da área, manutenção ou incremento da biodiversidade, manejo dos resíduos, conservação do solo e da água, entre outros (BRASIL, 2011).

Em respeito a este requisito legal, a totalidade dos produtores avaliados na Chapadinha expressou conhecer o termo, porém não possuem o documento teórico. Os produtores 7 e 8 relataram ter algum tipo de planejamento, porém, sem uma ordem lógica e não contemplando os pontos exigidos pela normativa. O produtor 6 relatou que a produção orgânica precisa de árduo trabalho e investimento de tempo, porque não têm um momento livre para o controle do Plano de Manejo da produção. Encontra-se que este mesmo caso apresenta-se no trabalho feito por Pinheiro (2012), salientando que, em se tratando do plano de manejo, todos os produtores pertencentes à APEP relataram ter ouvido alguma vez durante a prática da agricultura orgânica, mas não sabiam exatamente como se elabora e qual o conteúdo desse requisito, sendo esta outra exigência legal que nenhum dos produtores possuía. No caso dos produtores da Chapadinha, a insuficiente capacitação em tópicos como o conhecimento e cumprimento da normativa orgânica necessária para a construção de planejamentos produtivos segue representando uma barreira para que o produtor possa assegurar e demostrar a qualidade orgânica dos seus produtos.

\subsection{O processo de comercialização dos produtos}

O Decreto n. 6.323 de 2007, em seu capítulo III, seção I, inclui disposições pontuais sobre os requerimentos da comercialização de produtos orgânicos, relacionados com aspectos como uma proteção contínua para que não se misturem com produtos não orgânicos e não tenham contato com materiais e substâncias cujo uso não esteja autorizado para a produção orgânica; uma diferenciação visual dos produtos convencionais não orgânicos, sendo mantidos em espaços delimitados e identificados e ocupados unicamente por produtos orgânicos; e como aspecto fundamental a identificação do fornecedor no espaço de exposição (BRASIL, 2007).

Para avaliar os conhecimentos da normativa relacionados com a comercialização de produtos orgânicos foram estabelecidos dois pontos críticos: isolamento de produtos orgânicos dos convencionais e identificação do fornecedor no mercado.

\subsubsection{Isolamento de produtos}

Pode existir a possibilidade de que sejam produzidos e comercializados na mesma unidade produtiva produtos convencionais e orgânicos ao mesmo tempo, pelo qual vai existir um risco importante de contaminação e uma possibilidade de misturar os produtos (NEUENDORFF e STEINHAUSER, 2006). Conforme Fonseca et al. (2009), os produtos convencionais têm alta quantidade de resíduos de agrotóxicos que consistem em uma substância ou mistura de substâncias remanescentes ou existentes em alimentos, decorrente do uso ou da presença de agrotóxicos e afins, consideradas tóxicas, as quais, ao fazer contato com um produto orgânico, podem contaminá-lo, pelo qual deve ser permanentemente isolado e diferenciado dos produtos convencionais. 
372 - Normativa de Produção Orgânica no Brasil: a percepção dos agricultores familiares do assentamento da Chapadinha, Sobradinho (DF)

Na Chapadinha, todos os produtores entrevistados cumprem com esta exigência, pois sua produção é orgânica em toda a propriedade e a comercialização é feita de forma associada e com a participação de todos os produtores orgânicos. A diferenciação do produto no mercado ocorre mediante o desenvolvimento de atividades de seleção, lavagem e uso de embalagens diferenciadas, com objetivo de torná-los mais atrativos aos clientes.

No entanto, ao questionar se os produtores tiveram conhecimento específico dos aspectos estabelecidos na normativa orgânica, todos informaram que não tinham certeza de quais deveriam ser esses requerimentos. A produtora 8 ressaltou que é evidente a diferenciação dos produtos orgânicos em relação aos convencionais nas feiras livre. Embora os locais de ambos tipos de produtos estejam próximos e os produtores orgânicos sejam os únicos da feira, os clientes reconhecem a qualidade visual e nutricional dos produtos orgânicos, valorizando seu esforço de produzir alimentos saudáveis.

O transporte dos produtos também é feito isoladamente, tentando manter a qualidade. Segundo a produtora 2 (a dona do caminhão que leva os produtos da associação para a feira), o manejo dos produtos deve também ser diferenciado, levando a quantidade certa, em caixas que protejam e conservem o produto, e num caminhão limpo, dedicado exclusivamente ao transporte deles.

Evidencia-se que embora os produtores avaliados na Chapadinha não tenham conhecimentos técnicos dos requerimentos da comercialização estabelecidos na normativa, estão cumprindo com eles e reconhecem sua importância no mercado. Além disso deve-se reconhecer sua organização na associação, que contribui nas negociações, as quais são feitas de forma coletiva visando sempre diferenciar seus produtos de seus concorrentes e manter uma boa reputação no mercado (FONSECA et al., 2009).

\subsubsection{Identificação do fornecedor no mercado}

O comércio de produtos orgânicos no Brasil e no mundo depende da relação de confiança entre produtores e consumidores. Mas, para que isso aconteça, a venda direta para o consumidor final é de muita importância; é a partir dela que são estabelecidos preços mais justos e o produtor tem a oportunidade de mostrar sua preocupação com o cultivo dos alimentos que, no caso dos orgânicos, leva em conta o respeito à natureza e à saúde do homem, utilizando técnicas especiais (MAPA, 2008).

De acordo com a Lei n. 10.831 de 2003 os produtos orgânicos não certificados não podem fazer uso do Selo do Sistema Brasileiro de Avaliação da Conformidade Orgânica, mas a legislação permite que o agricultor coloque no rótulo do produto, quando existir, ou no ponto de venda, a expressão: Produto orgânico para venda direta por agricultores familiares organizados, não sujeito à certificação (BRASIL, 2003).

Este ponto da norma é bem conhecido pelos oito produtores entrevistados, que relataram que as capacitações recebidas foram enfáticas ao expor as repercussões e penalidades de comercializar um produto como orgânico sem ter nenhum tipo de certificação. Por isso, o produtor 6 se lembra que, no período de transição agroecológica, no momento de vender seu produto na feira, eles falaram a seus clientes que seus produtos eram naturais, sem químicos, mas nesse período nunca falaram que eles foram orgânicos.

Uma vez vinculados à Organização de Controle Social (OCS), começaram a comercializar seus produtos como orgânicos. Segundo o produtor 4, a declaração de produtores orgânicos obtida até o momento é sua identificação na feira e deve ser apresentada ao cliente sempre para ganhar e manter sua confiança neles como produtores orgânicos. 


\subsection{Mecanismos de controle}

Quanto aos mecanismos de controle, o Decreto n. 6.323 de 2007, em seu capítulo V, seção I, estabelece uma série de requisitos e responsabilidades para os produtores. Mesmo assim, define medidas cautelares como a apreensão temporária de produtos, a interdição temporária de estabelecimentos, a retirada temporária do cadastro de agricultores familiares e a suspensão temporária de credenciamento como organismo de avaliação da conformidade. O capítulo VII institui uma série de penalidades administrativas como advertência, multas, suspensão da comercialização do produto, condenação de produtos, rótulos, embalagens e matérias-primas, inutilização do produto, suspensão do credenciamento, da certificação, da autorização, do registro ou da licença e cancelamento do credenciamento, da certificação, da autorização, do registro ou da licença.

Na Chapadinha, o órgão fiscalizador é a OCS, que deve manter atualizadas as listas dos principais produtos e quantidades de produção por unidade de produção familiar, além de recolher a declaração de cadastro de produtor que for excluído. Com base nestas informações, o órgão fiscalizador passa a manter atualizado o Cadastro Nacional de atividades produtivas do Ministério da Agricultura, Pecuária e Abastecimento.

O ponto crítico analisado para a unidade de análise foram os conhecimentos dos produtores avaliados na Chapadinha sobre as medidas de fiscalização e penalidades administrativas, evidenciando que os produtores conhecem alguns destes mecanismos de controle, principalmente os relacionados com penalidades administrativas, os quais são mais severos com eles e podem prejudicar suas atividades. Até o momento, a comunidade tem trabalhado para prevenir qualquer tipo destas medidas, pois, segundo a produtora 7, qualquer erro cometido por uma pessoa vai afetar sua associação e a reputação da comunidade como a produtora orgânica que é na atualidade.

\subsection{Certificação}

O Decreto n. 6.323 de 2007, no título III do capítulo V, estabelece os parâmetros a respeito dos mecanismos de controle dispostos no Art. 25 , onde as pessoas físicas ou jurídicas, de direito público ou privado, que produzam, transportem, comercializem ou armazenem produtos orgânicos ficam obrigadas a promover a regularização de suas atividades junto aos órgãos competentes. Aqueles órgãos são reconhecidos pela IN 64 de 2008, no Art. 2 do anexo I, que trata do regulamento técnico para os sistemas orgânicos de produção animal e vegetal, como os organismos de avaliação da conformidade orgânica (OAC), definidos como as instituições que avaliam, verificam e atestam que produtos ou estabelecimentos produtores ou comerciais atendem ao disposto no regulamento da produção orgânica, podendo ser uma certificadora ou Organismo Participativo de Avaliação da Conformidade Orgânica (OPAC). De acordo com o exposto pela normativa foram avaliados dos pontos críticos referentes à certificação:

\subsubsection{Cumprimento dos requisitos para a certificação}

Desenvolver um processo de certificação implica um esforço por parte do produtor de apropriar-se das normativas de produção orgânica e cumprir com as exigências estabelecidas. Como foi tratado na temática anterior, no caso dos produtores da Chapadinha, existem lacunas no conhecimento das normas, principalmente pela escassa capacitação. Mesmo assim produtores avaliados cumprem com os requisitos de produção, pois suas capacitações são concentradas neste item, mas sua limitante é a ausência de registros que ratifiquem suas práticas de produção e comercialização que são desenvolvidas de forma adequada. 
374 - Normativa de Produção Orgânica no Brasil: a percepção dos agricultores familiares do assentamento da Chapadinha, Sobradinho (DF)

\subsubsection{Mecanismo de certificação orgânica}

A certificação que reconhece os produtores como orgânicos, além de aumentar o preço dos produtos no mercado e gerar um prestígio aos produtores, entre outras vantagens, contribui com a melhoria da eficiência da parte técnica das propriedades devido ao fato de que os produtores devem realizar atividades de planejamento e controle da produção (OLIVEIRA et al., 2006). De acordo com isso, os produtores avaliados na Chapadinha reconhecem aquelas vantagens, mas expõem que a adequação aos requisitos burocráticos e os altos custos da certificação por auditoria fazem com que eles não possam obter o selo; da mesma forma, os produtores relatam que, ainda que os Sistemas Participativos sejam uma alternativa, também incorrem nas mesmas limitações, salientando que os custos da certificação por meio deste mecanismo são mais baixos.

Neste sentido, Dulley (2003) expõe que os altos custos, as dificuldades técnicas e culturais que os produtores devem enfrentar no momento de adotar e cumprir com os requisitos técnicos exigidos na normativa podem tornar a certificação inacessível. Medaets e Fonseca (2005) relatam que as normativas e regulamentações podem ocasionar confusão tanto na sua interpretação quanto na prática por parte dos produtores, principalmente na agricultura familiar, voltando o pequeno produtor para um caminho difícil de transitar para o sucesso da certificação (MEDAETS e FONSECA, 2005).

Por fim, a totalidade dos produtores avaliados está certificada pelo mecanismo de certificação OCS, não havendo necessidade de investimento na certificação. Para estes casos, a norma permite algumas exceções, como a inexigibilidade do selo que diferencia os produtores orgânicos.

\section{Conclusões}

O presente trabalho objetivou determinar o grau de conhecimentos e aderência dos produtores avaliados da Chapadinha às normativas de produção orgânica estabelecidas no Brasil, para o qual foram estabelecidos os pontos críticos da compilação de três das legislações mais importantes: Lei n. 10831 de 2003; Decreto n. 6323 de 2007 e a Instrução normativa 46 de 2011. A partir da pesquisa, foram identificados aspectos legais que podem ser contatados como dificuldades para desenvolver um processo de certificação orgânica formalizado, o qual está ocorrendo na Chapadinha com o início dos Sistemas Participativos de Avaliação da Conformidade Orgânica. Nesse contexto, foram obtidas as considerações finais a seguir.

Uma das principais exigências da normativa orgânica no Brasil são os registros de todas as atividades desenvolvidas dentro da propriedade. Este aspecto constitui-se como a principal dificuldade dos produtores avaliados na Chapadinha, pois as diretrizes dos sistemas de produção orgânica que foram avaliadas (rastreabilidade, processo de conversão e plano de manejo) baseiam-se em registros para cada aspecto que o produtor deve levar de forma permanente. Estes requisitos dispostos pela normativa são complexos para os pequenos produtores familiares, além de que é escassa a capacitação relacionada com a correta elaboração desses documentos. Os produtores salientaram que a produção orgânica precisa de sua dedicação de tempo completo, e levar uma documentação tão específica é difícil para eles, pois todos trabalham sozinhos ou com ajuda de sua família. Evidentemente, a documentação é o maior gargalo no processo de certificação de pequenos produtores.

No processo de comercialização, foi evidenciado que embora os produtores avaliados na Chapadinha não tenham um conhecimento pontual dos itens que estabelecem a normativa, suas atividades são adequadas, praticando sempre o isolamento e a diferenciação de seu produto, aproveitando a boa organização de sua associação. Além disso, são conscientes da importância da identificação do fornecedor no mercado, percebendo este aspecto como a forma de ganhar confiança e credibilidade no mercado de orgânicos e evitar qualquer tipo de penalidade. 
Em relação aos mecanismos de controle estabelecidos na normativa, o grau de conhecimento dos produtores é baixo, pois conhecem algumas das repercussões de violar a normativa. Os produtores preocupam-se mais por aplicar ações preventivas para evitar essas medidas e tentam sempre manter sua reputação como um grupo de produtores orgânicos familiares reconhecidos no DF.

São necessários um maior aprofundamento e acompanhamento por parte das entidades de assistência técnica com relação ao registro e documentação das atividades de produção orgânica. É necessário criar consciência nos produtores sobre a importância destes registros, mostrando-lhes que é uma atividade simples e que pode ser convertida em uma prática da rotina.

\section{Referências}

ALVES, A. C. O. et al. Agricultura orgânica no Brasil: sua trajetória para a certificação compulsória. Rev. Bras. de Agroecologia, v. 7, n. 2, p. 19-27, 2012

ANGEOLETTO, F. et al. Associação Ecovida de Certificação Participativa recebe auditoria para manutenção de credenciamento. Brasil, 2012. Disponible en: <http:// www.ecovida.org.br/category/a-rede/certificacao/>. Acceso: jun. 2013.

BRASIL. Instrução Normativa no 7 de 17/05/1999. Disponível em: <file:///E:/MIS\%20DOCUMENTOS/ Downloads/IN_07_\%2017Mai1999.pdf>. Acesso em: maio, 2014.

- Ministério da Agricultura, Pecuária e Abastecimento. Lei № 10831, de 23 de dezembro de 2003. Publicado no Diário Oficial da União, Brasília, 2003, Seção 1, Página 8.

Ministério da Agricultura, Pecuária e Abastecimento. Decreto № 6.323, de 27 de dezembro de 2007. Publicado no Diário Oficial da União, Brasília, 2007. Seção 1, Páginas 2 a 8.

. Instrução normativa $\mathrm{n}^{\circ} \mathbf{4 6}$, de 06 de outubro de 2011. Lei no 10831, de 23 de dezembro de 2003. Diário Oficial da República Federativa do Brasil, Poder Executivo, Brasília, DF, 06 Outubro. 2011. Seção 1, p. 8.a

Ministério da Agricultura, Pecuária e Abastecimento. Caderno do plano de manejo orânico/ Ministério da Agricultura, Pecuária e Abastecimento.
Secretaria do desenvolvimento agropecuário e extrativismo. -Brasília:MAPA/ACS, 2011. 56p.b

CAMARGO, C. P. et al. Qualidade e Certificação de Produtos Agropecuários. Brasília. Embrapa Informação Tecnológica, 2002, 188 p.

DE AQUINO, A. M. e DE ASSIS, R. L. Agroecologia: princípios e técnicas para uma agricultura orgânica sustentável. Brasília, DF. Embrapa Informação tecnológica, 2005

DE JESUS, E. L. Diferentes abordagens de Agricultura não convencional: História e filosofia. In: Agroecologia: princípios e técnicas para uma agricultura orgânica sustentável. Brasília, DF: Embrapa Informação tecnológica, 2005. $517 \mathrm{p}$.

DULLEY, R. D. Estrutura produtiva e adequação ao sistema de produção orgânico. Informações Econômicas, São Paulo, v. 33, n. 11, 2003.

FETRAF-BRASIL-FederaçãoNacionaldosTrabalhadores e Trabalhadoras na Agricultura Familiar. Assentamento Chapadinha realiza V Feira da Agricultura Familiar. Brasília, Brasil. 2012. Disponível em: <http://www.fetraf.org. br/agencia-de-noticias/403/assentamento-chapadinharealiza-v-feira-da-agricultura-familiar >. Acesso: 29 abr. 2014.

FIGUEIREDO, E. A. P. e SOARES, J. P. G. Sistemas orgânicos de produção animal: dimensões técnicas e econômicas. In: REUNIÃO ANUAL DA SOCIEDADE BRASILEIRA DE ZOOTECNIA, 49. 2012, Brasília. A produção animal no mundo em transformação: anais. Brasília, DF: SBZ, 2012. 1 CD-ROM.

FOAM - International Federation of Organic Agriculture Movements. Documento de Politica IFOAM: Cómo los gobiernos pueden apoyar a los Sistemas Participativos de Garantía (SPG). Argentina, 2010.

. e FIBL - Research Institute of Organic Agriculture. Organic world.Global organic farming statistics and news. Data tables FiBL-IFOAM, 2014. Disponível em: <http://www.organic-world.net/ statistics-fao.html>. Acesso em: 28 abr. 2014.

FONSECA, M. F et al. Agricultura orgânica: introdução às normas, regulamentos técnicos e critérios para o aceso ao mercado de produtos orgânicos no Brasil. Manual técnico 19. Niterói - RJ. Programa Rio Rural, 2009. $58 \mathrm{p}$.

GALINDO, I. M. Regional development through knowledge creation in organic agriculture. Journal of Knowledge Management, v. 11, n. 5, f. 87-97, 2007. 
376 - Normativa de Produção Orgânica no Brasil: a percepção dos agricultores familiares do assentamento da Chapadinha, Sobradinho (DF)

MAPA - Ministério da Agricultura, Pecuária e Abastecimento. Controle social na venda direta ao consumidor de produtos orgânicos sem certificação. Secretaria de Desenvolvimento Agropecuário e Cooperativismo. Brasília: Mapa/ACS, 2008. 24 p. Disponível em: < http:// www.planetaorganico.com.br/arquivos/CONTROLE_ SOCIAL.pdf> Acesso em: 6 maio 2014.

- Produtos orgânicos: o olho do consumidor. Brasília, 2009. 32 p.

- Orgânicos. Brasil, 2014. Disponível em: <http://www.agricultura.gov.br/desenvolvimentosustentavel/organicos >. Acesso em: abr. 2014.

MEDAETS, J. P. e FONSECA, M. F. Produção orgânica: regulamentação nacional e internacional. Brasília: Ministério do Desenvolvimento Agrário, NEAD. 2005.

MOE, T. Perspectives on traceability in food manufacture. Trends in Food Science \& Technology, v. 9, n. 5, p. 211-214, 1998.

NEUENDORFF, J. e STEINHAUSER, C. Exportación de Productos Orgánicos de Países Terceros a la Unión Europea. Ministerio Federal de Alimentación, Agricultura y Protección al Consumidor (BMELV) en el Marco del Programa Federal Agricultura Orgánica. Göttingen, 2006.
OLIVEIRA, R. A. et al. O consumo e comercialização de produtos orgânicos: o caso da associação para o desenvolvimento da agropecuária orgânica. In: Congresso da sociedade brasileira de economia, administração e sociologia rural. Fortaleza: SOBER, 2006.

. et al. Produção Orgânica de Citros no Rio Grande do Sul. EMBRAPA. Brasil, 2011. ISSN 1806-9207.

ORMOND, J. G. P. et al. Agricultura Orgânica: Quando o Passado é Futuro. BNDES Setorial, Rio de Janeiro, n. 15, p. 3-34, mar. 2002.

PINHEIRO, K. H. Produtos orgânicos e certificação: o estudo desse processo em uma associação de produtores do município de palmeira - PR. Dissertação (Mestre em Engenharia de Produção). Programa de Pós-Graduação em Engenharia de Produção. Universidade Tecnológica Federal do Paraná - Campus Ponta Grossa. 2012.

PROCHILE. Tendencias del Mercado. Productos Orgánicos en Brasil. Documento elaborado.

RABELLO, T. Um mapa parcial da agricultura orgânica no País, mas com números confiáveis. Brasil, 2012.

SILVA, A. F. Perfil sensorial da bebida de café (Coffea arabica l.) orgânico. Tese Programa de Pós-graduação em Ciência e Tecnologia de Alimentos. Viçosa Minas Gerais. Brasil, 2003. 112 p. 